\title{
Public Health and Primary Care: Expanding the Role
}

\author{
Peter G. Fitzpatrick, Ed.D., R.Ph ${ }^{1}$, Marcia K. Butler, Rdh, Drph ${ }^{2}$ \\ Kendolyn Smith, Pharmd, Mph ${ }^{3}$, John M. S. Bryan, Ph.D ${ }^{4}$ \\ ${ }^{1}$ Healthcare Management Program, College of Health, Clayton State University, Morrow \\ ${ }^{2}$ Healthcare Management Program, College of Health, 2000 Clayton State Blvd, Morrow \\ ${ }^{3}$ Healthcare Management Program, College of Health, Clayton State University, Morrow \\ ${ }^{4}$ Healthcare Management Program, College of Health, Clayton State University, Morrow \\ peterfitzpatrick@clayton.edu
}

Abstract: The demand for primary care services in the United States is currently not being fully met. Ageing and demographic changes indicate the gap between demand and supply will continue to widen. Provisions within the Affordable Care Act will attempt to increase the supply of primary care physicians. Sadly, past experience does not inspire us with confidence that these efforts will work. Public health departments are often ignored in terms of the role that they play in providing primary care. This paper identifies the need for additional primary care services and outlines a proposal to allow public health entities help satisfy this need.

Keywords: Public Health; Primary Care; Primary Care Physicians; Models of Care; Public Health Services; Access.

\section{INTRODUCTION}

A clear argument can be made that the essence of public health is a collective exercise to create environments where people can be healthy (Tilson \& Berkowitz, 2006). The nature of what it means to be healthy has been changing. The greatest challenges to health are now chronic diseases: cardiovascular disease, cancer, hypertension, asthma, and diabetes (Mayes \& Armistead, 2013). Within the developed countries chronic diseases consume the largest percentage of health care expenditures (Schroeder, 2007). In the United States this problem is even greater as chronic diseases account for $75 \%$ of our health care expenditures (Centers for Disease Control and Prevention, 2009). If we accept the premise that the essence of public health is to keep people healthy, then the inclusion of public health into primary care becomes logical. It also becomes evident, and economically necessary, that primary care focus more on reducing the impact of chronic diseases.

An almost constant refrain is that the United States is spending too much money on health care. The current estimate is that we are spending almost $20 \%$ of our Gross Domestic Product for health care and this could rise to $25 \%$ by 2025 (Congressional Budget Office, 2011). Based upon the current cots of chronic diseases and the projections of future costs, the control of health care spending will require significant reductions in the impact of chronic diseases. Here is where we believe a greater focus on primary care can produce very meaningful results. Public health should provide a much greater role in this reduction.

\section{ASSESSMENT OF PRIMARY CARE SERVICES}

The United States health delivery system is complex due to the nature of the ideals of healthcare that exist within the population. The United States lacks a single national entity or set of policies guiding the health care system; physicians and hospitals practicing in the same community and caring for the same patients are not connected to each other (Doctors for America, 2015). It should be of note that when the health reform initiatives were originally initiated, there were issues of declining health insurance and also increasing cost for the care 
within the United States. However, "a third crisis also has captured the attention of policy makers; the decline of primary care." (Bodenheimer, 2010). The Starfield pillars of primary care identified four features of primary care services: first-contact access for each need; long-term person- (not disease) focused care; comprehensive care for most health needs; and coordinated care when it must be sought elsewhere (Bodenheimer, 2010). The Institute of Medicine's definition of primary care is consistent with ensuring that integrated, accessible health care services are provided and that there are clinicians who are accountable for addressing a large majority of personal health care needs (Institute of Medicine [IOM], 2010). In 2010, research by the Agency for Healthcare Research and Quality (AHRQ) noted that the number of practicing primary care physicians in the United States was approximately 209,000 (Agency for Healthcare Research and Quality [AHRQ], 2010). More recent data from the Kaiser Family Foundation's State Health Facts reports that as of June 2015 notes that the number of totally active primary care physicians in the United States is 430,150 (Kaiser Family Foundation [KFF], 2015). California has the highest number of active primary care physicians with 49,112, followed by New York $(35,569)$ and Texas $(27,859)$. The other top 10 states where the most primary care physicians are practicing in the United States are identified in Table 1.

In terms of populations of patients within the United States, there is a wide variety of differences among communities. The needs for services vary depending on whether the community is rural or urban. Only about 11 percent of the nation's physicians work in rural areas, despite nearly 20 percent of Americans living there (National Conference of State Legislators [NCSL], 2012). Primary Care will be challenged to address the needs of all populations, which are transforming the services and partnerships of the past. According to The John's Hopkins Primary Care Policy Center, "Primary Health services" are defined as (1) health services related to family medicine, internal medicine, pediatrics, obstetrics, or gynecology, (2) diagnostic laboratory and radiologic services, (3) preventative health services, (4) emergency medical services and (5) pharmaceutical services. In reality, not all services are provided as robustly as others within different segments of our communities. There are traditional facilities where primary care services are offered in the United States that include single practices, group practices, managed care organizations, public health facilities and corporations. Today, there are also emerging, non-traditional facilities, including emergency departments, specialty care centers, school wellness areas and workplace wellness centers. Whether traditional or non-traditional, issue of access, quality and cost still are essential components to address, along with how to keep facilities in compliance, utilize additional practitioners and adapt to changes in health care for sustainability.

Table 1: Top 10 States with the highest number of Primary Care Physicians

\begin{tabular}{|c|c|}
\hline STATE & Primary Care Physicians \\
\hline California & 49,112 \\
\hline New York & 35,569 \\
\hline Texas & 27,859 \\
\hline Florida & 24,609 \\
\hline Pennsylvania & 21,167 \\
\hline Illinois & 19,480 \\
\hline Ohio & 17,466 \\
\hline Michigan & 16,257 \\
\hline Massachusetts & 14,005 \\
\hline New Jersey & 13,294 \\
\hline
\end{tabular}

Volume 2016

Page 2 


\section{MODELS OF CARE}

There are new models of care that are gaining interest in the United States. Some practices can now become certified Patient Centered Medical Homes (PCMH). Other models of care are also being considered to improve outcomes and focus on collaborative health care. The new programs and services must be unique to the area rather than just transitioning urban focused programs to rural communities. With the ACA, the problem is expected to get bigger as more people are being driven into the healthcare system. Unfortunately, few communities have the funding, facilities or the number of providers to accommodate their additional needs. Options for providing additional care through existing rural providers include, expanding services to nurse practitioners (NP's), Physician Assistant's (PA's), Pharmacists and other non-physician health professionals currently engaged with patients to improve the outcomes within their impacted communities. PCMH models allow patients to be engaged with a team of healthcare professionals, including their provider in order to begin the process of transforming health care to a more integrated approach that is appropriate and includes access to community resources when there is a need.

The Integrated Health Model (IHM) is another option of inclusive use of physician and non-physician professionals. Some of the IHM features are designed to incorporate more specific health needs, such as Mental Health and Behavioral Health. In seeking to integrate care through these new models, the outcomes are improved and the cost of care becomes less when access is more readily available.

According to Healthy People 2020, access to healthcare is important for (1) overall physical, social, and mental health status, (2) prevention of disease, (3) detection and treatment of illness, (4) quality of life, (5) preventable death and (6) life expectancy.

\section{FUTURE OF PRIMARY CARE}

Public Health and Primary Care are aligned in their goals but have historically worked as independent entities. In an effort to provide care that is based on equity, the complexities of cost, quality and access to care continues to remain critically important in determining how to ensure that health delivery become exemplary for all. The next decade should be aligned with moving toward an integrated system instead of factions between public health and primary care. In rural communities, access to primary care is essential in providing for physical, social and mental health services, prevention of disease, detection and treatment of illnesses, quality of life, preventable death and life expectancy. There are significant gaps within the rural health care system. The most common gaps are cost, quality and access.

Although public health and primary care are focused on similar goals in providing care and services, they have typically operated as their own independent entities. In considering where there are opportunities to make changes that will better align the two; there are many factors that are important. In many instances, gaps exist for rural communities that do not occur in urban areas. There is a new challenge for public health as it strives to meet the needs of populations of patients but individualize the approach toward ensuring optimized cost, quality and access to health needs. Gaps that are perceived and realized remain to be cost, quality and access to care. Access is the most likely to be impacted significantly impacted in rural areas. Based on the 2012 Institutes of Medicine's (IOMs) Brief on Primary Care and Public Health: Exploring Integration to Improve Population Health, new opportunities are emerging to bring these two areas together. However, it will not be a short- term simple fix; rather there will be various phases of change due to differences between communities based on needs, social climate and expertise. Additionally, local, state and federal agencies have been tasked with continuing to make strides toward partnerships between primary care and public health. It is well understood that mutual awareness may be considered a big accomplishment in some communities, while cooperation and collaboration will be huge milestones in other communities. Figure 1 identifies the manner in which integration will take place if it is to happen between public health and primary care.

Volume 2016

Page 3 
Fig.1. Integration of Public Health and Primary Care

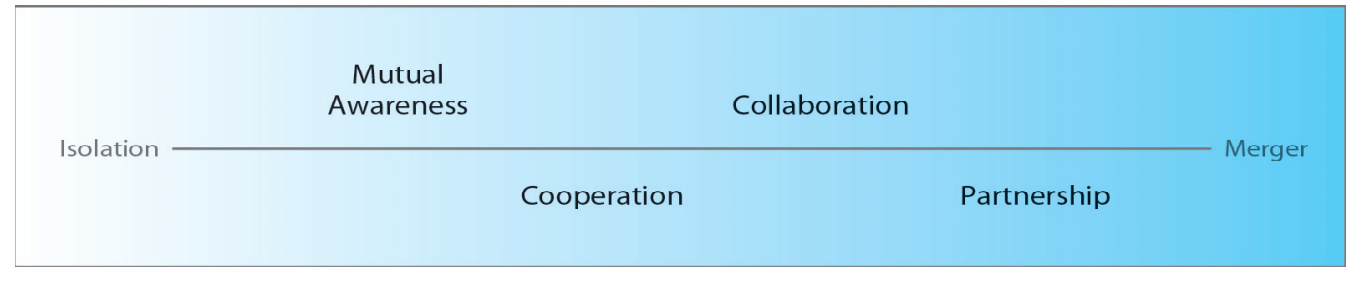

Source: IOM, Institutes of Medicine Brief, March 2012

The Role of local Public Health Departments in the Delivery of Primary Care SERVICES

The 2002 report by the IOM The Future of the Public's Health in the $21^{\text {st }}$ Century, reiterates the definition of public health as "What we as a society do collectively to assure the conditions in which people can be healthy" (IOM, 2003, p. 28). The three core areas of public health are assessment, assurance and policy development and include ten essential functions (Figure 2). The pillar of the public health system is the Local Health Department (LHD). There are approximately 2,800 LHDs in the United States (NACCHO, 2014) that are legally required to provide the essential public health services within their communities (IOM, 2012a, p. 3). The size of the communities which LHDs serve range from populations of less than 10,000 to populations over 1,000,000 (NACCHO, 2014). Because of the varied population differences there are also multiple levels of jurisdictions that include city, metropolitan, county, and tribal units or multi-county regions or districts. In addition to these multiple jurisdictions, there are different funding schemes within the state and local governments that help finance the services provided, as well as a diverse public health workforce to provide those services. For these reasons, the scope of public health services within these communities vary tremendously from providing surveillance services to clinical services.

Figure 2: Ten Essential Public Health Services

\begin{tabular}{|rl|}
\hline Assessment \\
\hline 1. & Monitor health status to identify community health problems \\
2. & Diagnose and investigate health problems and health hazards \\
\hline Policy Development \\
\hline 3. & Inform, educate, and empower people about health issues \\
4. & Mobilize community partnerships to identify and solve health problems \\
5. & Develop policies and plans that support individual and community health efforts \\
\hline Assurance \\
\hline 6. & Enforce laws and regulations that protect health and ensure safety \\
7. & Link people to needed personal health services and assure the provision of health care \\
8. & Assen otherwise unavailable a competent public health and personal health care workforce \\
9. & Evaluate effectiveness, accessibility, and quality of personal and population-based health \\
& services \\
\hline Serving All Functions \\
\hline 10.
\end{tabular}

Source: Public Health Functions Steering Committee (1994)

Volume 2016 
The National Profile of Local Health Department Study Series (Profile Survey) is a survey conducted by the National Association of County and City Health Officials (NACCHO) for local health departments to determine the public health services that LHDs currently provide, which may include environmental services, population-level services or individual-level clinical services (primary care). This Profile Survey has been administered several times from 1989 to 2013. This study utilized the 2013 LHD Profile Survey, which had a response rate of 79\% representing over 2,532 LHDs to determine the scope of primary care services provided. This survey was selected because it provides the most current representative sample of primary care services after the budget crisis from 2008 and prior to the implementation of the ACA. The primary care services were divided into four categories provided by the LHDs. These categories were immunizations, maternal and child health $(\mathrm{MCH})$, chronic disease management, and other services.

The results from the 2013 Profile Survey, indicates that the most common public health services provided by LHDs are population-based. Ninety-one percent of local health departments provide communicable and infectious disease surveillance programs, $90 \%$ provide adult and child immunizations, and $83 \%$ provide Tuberculosis screenings (NACCHO, 2014). In addition, environmental health surveillance programs were provided by $78 \%$ of the LHDs (NACCHO, 2014). The primary care services provided are diverse and are dependent upon the size of the community. A larger percentage of primary care services are more common among LHDs who serve larger populations.

Although immunizations can be classified as a population-health program, it is also considered to be a primary care service and as previously mentioned, is the most common service offered by LHDs. Among the maternal and child health (MCH) services offered, $60 \%$ of LHDs of any size provided maternal and child home health care visits and $54 \%$ provided family planning services. A little more than $30 \%$ of the LHDs provided any type of clinical services such as early periodic screening, diagnosis or treatment (EPSDT) programs (36\%) or well-child care clinics (32\%) and even fewer offer obstetrical care (8\%) (Table 2). Chronic disease management services are provided by half of the LHDs, where only $11 \%$ of all LHDs provide comprehensive care services. Among all LHDs, high blood pressure screenings (57\%) were the most commonly offered screening program and cardiovascular screening (27\%) the least offered. Behavioral/mental health services and substance abuse programs were the lease likely programs to be provided across all LHDs.

Table 2: LHDs Primary Care Services Provided (\%) by Population Serveda

\begin{tabular}{|c|c|c|c|c|c|c|}
\hline Services & All LHDs & $<25,000$ & $\begin{array}{l}25,000- \\
49,999\end{array}$ & $\begin{array}{l}50,000- \\
99,000\end{array}$ & $\begin{array}{l}100,000- \\
499,999\end{array}$ & $500,000+$ \\
\hline \multicolumn{7}{|l|}{ Immunizations } \\
\hline Adult Immunizations & $90 \%$ & $87 \%$ & $92 \%$ & $94 \%$ & $93 \%$ & $92 \%$ \\
\hline Child Immunizations & $90 \%$ & $85 \%$ & $92 \%$ & $93 \%$ & $92 \%$ & $95 \%$ \\
\hline \multicolumn{7}{|c|}{ Maternal and Child Health } \\
\hline EPSDT $^{\mathbf{b}}$ & $36 \%$ & $36 \%$ & $37 \%$ & $37 \%$ & $37 \%$ & $38 \%$ \\
\hline Family Planning & $54 \%$ & $50 \%$ & $55 \%$ & $57 \%$ & $61 \%$ & $63 \%$ \\
\hline $\mathrm{MCH}^{\mathrm{c}}$ Home Visits & $60 \%$ & $53 \%$ & $57 \%$ & $66 \%$ & $68 \%$ & $78 \%$ \\
\hline Prenatal Care & $27 \%$ & $20 \%$ & $27 \%$ & $34 \%$ & $32 \%$ & $35 \%$ \\
\hline Well Child Clinic & $32 \%$ & $29 \%$ & $31 \%$ & $36 \%$ & $35 \%$ & $33 \%$ \\
\hline Obstetrical Care & $8 \%$ & $5 \%$ & $8 \%$ & $9 \%$ & $14 \%$ & $18 \%$ \\
\hline \multicolumn{7}{|c|}{ Chronic Disease Management } \\
\hline Chronic Diseases & $50 \%$ & $42 \%$ & $48 \%$ & $54 \%$ & $60 \%$ & $72 \%$ \\
\hline
\end{tabular}

Volume 2016

Page 5 
American Research Journal of Business and Management (ARJBM)

\begin{tabular}{|c|c|c|c|c|c|c|}
\hline Diabetes Screening & $36 \%$ & $35 \%$ & $34 \%$ & $40 \%$ & $37 \%$ & $42 \%$ \\
\hline HBP $^{d}$ Screening & $57 \%$ & $62 \%$ & $57 \%$ & $58 \%$ & $49 \%$ & $50 \%$ \\
\hline CVD $^{\mathrm{e}}$ Screening & $27 \%$ & $23 \%$ & $26 \%$ & $32 \%$ & $29 \%$ & $39 \%$ \\
\hline Cancer Screening & $36 \%$ & $30 \%$ & $34 \%$ & $42 \%$ & $44 \%$ & $44 \%$ \\
\hline \multicolumn{7}{|l|}{ Other Services } \\
\hline Comprehensive $\mathrm{PC}^{\mathrm{f}}$ & $11 \%$ & $7 \%$ & $9 \%$ & $16 \%$ & $15 \%$ & $20 \%$ \\
\hline $\mathrm{APM}^{\mathrm{g}}$ & $19 \%$ & $13 \%$ & $16 \%$ & $21 \%$ & $26 \%$ & $44 \%$ \\
\hline $\mathrm{EMS}^{\mathrm{h}}$ & $3 \%$ & $2 \%$ & $1 \%$ & $3 \%$ & $5 \%$ & $17 \%$ \\
\hline Laboratory & $27 \%$ & $20 \%$ & $23 \%$ & $26 \%$ & $38 \%$ & $66 \%$ \\
\hline Home Health Care & $21 \%$ & $28 \%$ & $19 \%$ & $20 \%$ & $13 \%$ & $10 \%$ \\
\hline Behavioral or Mental & $10 \%$ & $7 \%$ & $8 \%$ & $12 \%$ & $14 \%$ & $28 \%$ \\
\hline Substance Abuse & $7 \%$ & $4 \%$ & $6 \%$ & $9 \%$ & $10 \%$ & $20 \%$ \\
\hline
\end{tabular}

Note. ${ }^{a}$ Data provided from the 2013 National Profile of Local Health Departments, by \%. ${ }^{b}$ EPSDT = early periodic screening, diagnosis, and treatment; ${ }^{\mathrm{C}} \mathrm{MCH}=$ maternal and child health; ${ }^{\mathrm{d}} \mathrm{HBP}=$ high blood pressure; ${ }^{\mathrm{e}} \mathrm{CVD}=$ cardiovascular disease; ${ }^{\mathrm{f}} \mathrm{PC}=$ primary care; ${ }^{\mathrm{g}} \mathrm{APM}=$ asthma prevention and management; ${ }^{\mathrm{h}} \mathrm{EMS}=$ emergency medical services

The IOM defines primary care services as "the provision of integrated, accessible healthcare services by clinicians who are accountable for addressing a large majority of personal health care needs, developing a sustained partnership with patients, and practicing in the context of family and community" (IOM, 2012a, p. 3). The majority of clinical services or primary care services that are provided by LHDs are critical to the communities for whom they serve and are in line with this definition. Currently there is some controversy among LHD leaders as to whether clinical services is critical to the overall core functions of public health because there is a multitude of players, both public and private organizations as well as individuals, that are intertwined in the public health system whose goals are to support the three core functions of public health (IOM, 2003, p. 28). However, some LHDs regard providing primary care services as part of their mission and as an essential function, especially to the vulnerable populations in their communities, as a safety net provider if there are not any other options due to a shortage of health professionals or services (Bekemeier, Pantazis, Dunbar \& Herting, 2014; Hsuan and Rodriguez, 2014). Nevertheless, there has been a decline in clinical services offered and currently only half of the LHDs still provide a range of primary care services to the uninsured and underinsured (IOM, 2012b, p. 66). The 2013 LHD Profile Survey, provides further evidence of the decreases in clinical services offered by all LHDs. Among the primary services offered, all of the screening services for diseases or conditions (diabetes, high blood pressure, cardiovascular, and cancer) saw a significant decrease from the 2005 LHD Profile Survey data (NACCHO, 2014). Specifically, diabetes screening decreased from $48 \%$ by all LHDs to $36 \%$ and cancer screenings decreased from $42 \%$ providing this service to $36 \%$ (Table 3 ).

Local Health Departments are facing challenges that will have an effect on providing direct primary care services. These challenges include changes in the public health workforce, continued reductions in state and local budgets, and the implementation of the Affordable Care Act (ACA). However, some LHDs are adapting to these changes by reducing their primary care services and expanding their population-based prevention services, while other LHDs will continue to support their primary care services by finding other ways to be reimbursed for the primary care services through third-party billing, or by collaborating with other healthcare providers in their communities. This may include forming an Accountable Care Organization (ACO) with other local entities or collaborating with federally qualified health centers. 
American Research Journal of Business and Management (ARJBM)

Table 3: LHDs Select Screening Programs for Diseases/Conditions (by Profile Study Years 2005 and 2013)

\begin{tabular}{|l|c|c|}
\hline Clinical Screening Program & $\mathbf{2 0 0 5}$ & $\mathbf{2 0 1 3}$ \\
\hline High Blood Pressure Screening & $69 \%$ & $57 \%$ \\
\hline Diabetes Screening & $48 \%$ & $36 \%$ \\
\hline Cancer Screening & $42 \%$ & $36 \%$ \\
\hline Cardiovascular Screening & $34 \%$ & $27 \%$ \\
\hline
\end{tabular}

Source: NACCHO, National Profile of Local Health Departments, 2013.

\section{LIMITATIONS}

As the National Profile of Local Health Department Survey is self-reporting, there are limitations to this survey that we must take into account when discussing the services and programs provided. First, this survey does not allow for LHDs to provide extensive details on the scope or scale of some of their services or programs. Second, this survey does not explicitly provide the definition of many of the 87 programs or services included, so the interpretation of the programs and services they provide may differ among the respondents. Third, some of the LHDs were given additional questions to answer, which may not convey the whole picture of the primary care services that are provided within all of the LHDs. However, this Profile Survey does provide very valuable information concerning the current state of local health departments and the public health services and programs that are offered.

\section{Public Health Model}

The divide between traditional medicine and public health has many roots, but probably the most significant is financial. When Medicare and Medicaid were developed to serve the elderly and the poor reimbursement was focused on treatment and not prevention. This created a basic divide between medicine and public health owing to financial incentives mainly being giving to medicine for procedures and dealing with major illness, rather than to public health and its role in prevention (Scutchfield, Michener, \& Thacker, 2012).

The separation of medicine and public health was further exacerbated during the 1970's and 1980's as greater emphasis was placed on cost containment in health care. Previously reimbursed primary care services performed by public health were no longer funded (Stephens, 1990). With this departure by public health from primary care a huge deficit was produced in the offering of these services. This deficit was especially acute in many rural areas and inner-city neighborhoods in the United States. The core of the problem seemingly rests with payment and reimbursement schemes. In general, in healthcare delivery we pay to do things. We undervalue cognitive and preventative services by not paying for them. What we believe needs to be created is a system that funds both prevention and primary care services: enter public health.

The recently initiated and upheld Affordable Care Act provides a variety of funding schemes that can combine preventative services with primary care services (Scutchfield et al., 2012). A number of these projects are available through the Centers for Disease Control (CDC). Our proposed model would use this funding to create within already existing public health facilities, primary care clinics staffed primarily by nurse practitioners, pharmacists, and health educators. Where possible, the range of these public health clinics could be increased by using mobile clinics. Services that would be provided would be modeled after those offered at clinics currently housed in many retail pharmacies. Additionally, our pharmacists would be available to do Medication Therapy Management (MTM) for conditions such as asthma, diabetes, and hypertension among others. Our 
health educators would provide diet and exercise education, smoking cessation programs, and any other health education programs that a specific area may need. Our goal is to provide health care services to the underserved, and to lower costs and improve outcomes. A condition that can serve as an illustration for our model is the afore mentioned asthma.

A study conducted to evaluate the cost of asthma revealed that for the years 2002 - 2007 the incremental direct cost was $\$ 3,259$ per person per year. Additionally, the cost of days lost per year was $\$ 301$ for each worker and $\$ 93$ for each student. For the year 2007, the total incremental cost for the United States was $\$ 56$ billion along with morbidity losses of $\$ 3.8$ billion, and productivity losses of $\$ 2.1$ billion (Barnett \& Nurmagambetov, 2011). The tragedy of these losses is that most of them are preventable. The key elements to better asthma management are high-quality health care, patient education, and optimizing the management of asthma (Follenwelder \& Lambertino, 2013). All of these elements would be addressed by our health care teams within the public health institutional settings. In addition, the adverse effects of asthma disproportionately affect blacks and the rural poor (Follenwelder \& Lambertino, 2013). We suspect that this is a pattern of a variety of diseases and conditions that our model would address. The recently initiated and upheld ACA provides a variety of funding schemes that can combine preventative services with primary care services (Scutchfield et al., 2012). A number of these projects are available through the Centers for Disease Control (CDC). Our proposed model would use this funding to create within already existing public health facilities, primary care clinics staffed primarily by nurse practitioners, pharmacists, and health educators. Where possible, the range of these public health clinics could be increased by using mobile clinics.

\section{CONCLUSION}

The need to reach the most disenfranchised of our citizens for their health care needs and services is clear. Much has been written and attempted and yet many basic problems still remain. With the seemingly inexorable increases in health care spending, and the ageing of our population, it would appear that true movement to serve the underserved probably won't happen any time in the near future. Our proposal is to use existing facilities, expand the presence of allied health care providers, and allow them to provide services which are currently not be offered in many areas. This is only a first step, and yet we feel a critical one if we are to produce solutions to this problem.

\section{REFERENCES}

Barnett, S.B., \& Nurmagambetov, T.A. (2013). Cost of asthma in the United States: 2002 - 2007. Journal of Allergy of Clinical Immunology, 127(1): 142-152.

Bekemeire, B., Pantazis, A., Dunbar, M. D., \& Herting, J. R. (2014). Classifying Local Health Departments on the Basis of the Constellation of Services They Provide. American Journal of Public Health, 104(12), e77-e82. doi: 10.2105/AJPH.2014.302281.

Bodenheimer, T., \& Pham, H. (2010). Primary Care. Health Affairs, 5(29), 799-805.

Centers for Disease Control and Prevention (2009). Chronic Disease Prevention and Health Promotion: Atlanta, GA.

http://www.cdc.gov/chronicdisease/resources/publications/AAG/chronic.htm.

Congressional Budget Office. The Long-term Outlook for Health Care Spending. Washington, DC: Congressional Budget Office; 2007. Available at: http://www.cbo.gov/ftpdocs//88xx/ doc8880/20071120_OrszagPresentation.pdf. 
Follenweider, L.M., \& Lambertino, A. (2013). Epidemiology of asthma in the United States. Nursing Clinics of North America, 48(1): 1-10.

Husan, C., \& Rodriguez, H. P. (2014). The Adoption and Discontinuation of Clinical Services by Local Health Departments. American Journal of Public Health, 104(1), 124-133.

doi: 10.2105/AJPH.2013.301426

IOM (Institute of Medicine). 2001. The Future of the Public's Health in the 21st Century. Washington DC: The National Academies Press.

IOM. 2012a. Primary Care and Public Health: Exploring Integration to Improve Population Health. Washington DC: The National Academies Press. Accessed September 28, 2015 http://www.nap. edu/catalog.php?record_id=13381

IOM. 2012b. For the Public's Health: Investing in a Healthier Future. Washington DC: The National Academies Press. Accessed September 29, 2015 http://www.nap.edu/catalog.php?record

IOM (Institute of Medicine). 1994. Defining Primary Care: An Interim Report. Committee on the Future of Primary Care. Washington, DC: National Academy Press

J. Cromartie, Population \& Migration (Washington, D.C.: U.S. Department of Agriculture, Economic Research Service, May 26, 2012), http://www.ers.usda.gov/topics/rural-economy-population/population-migration. aspx.

Mayes, R., \& Armistead, B. (2013). Chronic disease, prevention policy, and the future of public health and primary care. Medicine, Health Care \& Philosophy, 16: 691-697.

National Association of County and City Health Officials (NACCHO). 2013. National Profile of Local Health Departments. Washington DC: National Association of County and City Health Officials; 2013. Availableat: http://www.naccho.org/topics/infrastructure/profile/resources/2013report. Accessed August 1, 2015.

Phillips, C.D. \& McLeroy, K.R. (2004). Health in Rural America: Remembering the Importance of Place. American Journal of Public Health 94(10), 1661-1663.

Primary Care Workforce Facts and Stats No. 3. October 2014. Agency for Healthcare Research and Quality, Rockville, MD. http://www.ahrq.gov/research/findings/factsheets/primary/pcwork3/index.html

Public Health Functions Steering Committee. 1994. Public health in America, fall 1994. Available online at www. health.gov/phfunctions/public.htm

Schroeder, S. (2007). We can do better improving the health of American people. The New England Journal of Medicine, 357: 1221-1228.

Scutchfield, F.D., Michener, J.L., \& Thacker, S.B. (2012). Are we there yet? Seizing the moment to integrate medicine and public health. American Journal of Public Health, 102(53): S312-S316.

The United States lacks a single national entity or set of policies. (2015, September 14) Retrieved from http:// www.drsforamerica.org/learn/state-leader-resources

Tilson, H., \& Berkowitz, B. (2006). The public health enterprise: Examining our twenty-first century policy challenges. Health Affairs, 25: 900-910. 
(1995, May 15). Kaiser Family Foundation - Health Policy Research, Analysis, Polling, Facts, Data and Journalism. Total Professionally Active Physicians | Henry J. Kaiser Family Foundation. Retrieved September 13, 2015, from http://kff.org/other/state-indicator/total-active-physicians/

(1998, September 24). SAMHSA. Integrated Care Models. Retrieved September 3, 2015, from h tt p : / / w w w. integration.samhsa.gov/integrated-care-models

(2009, March 22). Doctors for America. Learn: Healthcare Delivery System. Retrieved September 1, 2015, from http://www.drsforamerica.org/

(2005, January 31). Healthypeople.gov. Retrieved September 4, 2015, from http://www.healthypeople.gov/

(1996, October 13). NCSL. Meeting the Primary Care Needs of Rural America: Examine the role of Non-Physician Providers. Retrieved September 13, 2015, from http://www.ncsl.org/research/health/meeting-the-primarycare-needs-of-rural-america.aspx

Citation: Peter G. Fitzpatrick, Ed.D., R.Ph', Marcia K. Butler, Rdh, Drph ${ }^{2}$ Kendolyn Smith, Pharmd, ${ }^{1} \mathbf{p h}^{3}$, John M. S. Bryan, Ph. ${ }^{4}{ }^{4}$, Public Health and Primary Care: Expanding the Role. ARJBM Volume 2016; pp:1-10

Copyright @ 2016 Peter G. Fitzpatrick, Ed.D., R.Ph ${ }^{1}$, Marcia K. Butler, Rdh, Drph ${ }^{2}$,Kendolyn Smith, Pharmd, $\mathbf{M p h}^{3}$, John M. S. Bryan, Ph.D ${ }^{4}$, This is an open access article distributed under the Creative Commons Attribution License, which permits unrestricted use, distribution, and reproduction in any medium, provided the original work is properly cited. 